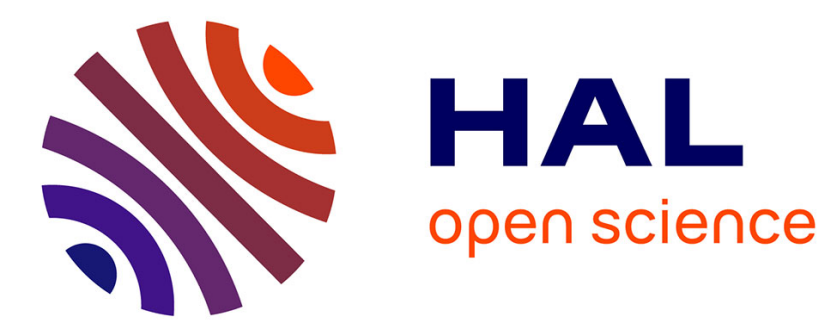

\title{
STRAIN CORRELATION AT DIFFERENT STRUCTURAL LEVELS FOR DYNAMICALLY LOADED HOLLOW COPPER CYLINDERS
}

\author{
M. Bondar, V. Nesterenko
}

\section{- To cite this version:}

M. Bondar, V. Nesterenko. STRAIN CORRELATION AT DIFFERENT STRUCTURAL LEVELS FOR DYNAMICALLY LOADED HOLLOW COPPER CYLINDERS. Journal de Physique IV Proceedings, 1991, 01 (C3), pp.C3-163-C3-170. 10.1051/jp4:1991321 . jpa-00250463

HAL Id: jpa-00250463 https://hal.science/jpa-00250463

Submitted on 1 Jan 1991

HAL is a multi-disciplinary open access archive for the deposit and dissemination of scientific research documents, whether they are published or not. The documents may come from teaching and research institutions in France or abroad, or from public or private research centers.
L'archive ouverte pluridisciplinaire HAL, est destinée au dépôt et à la diffusion de documents scientifiques de niveau recherche, publiés ou non, émanant des établissements d'enseignement et de recherche français ou étrangers, des laboratoires publics ou privés. 


\title{
STRAIN CORRELATION AT DIFFERENT STRUCTURAL LEVELS FOR DYNAMICALLY LOADED HOLLOW COPPER CYLINDERS
}

\author{
M.P. BONDAR and V.F. NESTERENKO
}

Lavrentyev Institute of Hydrodynamics, Siberian Division of the USSR, Academy of Sciences, Novosibirsk 630090, USSR

\begin{abstract}
A quantitative carnelation between continual values of strains and micrastrains have been determined. The plastic flaw instability in capper develaped inta the system of cracks, has been revealed. At high rate strain a succession of engagement of structural strain levels has been shaun ta be dependent on the siye of grain in an initial structure and to be determined by the relation between the values of mean strain rate at a cantinual level and the rate of internal stress accomadation due to ratational mades.
\end{abstract}

Structure-strained states of metals under explosive loading are of great interest in the study of bond formation at explosive welding and compacting. In [1] it is demonstrated that to obtain high-strength bonding by the above methods, plastic deformation should be localized in a certain region on contact surfaces. However, the strain correlation at different structural levels at dynamic loading and shear localization conditions at a macrolevel are difficult to be determined experimentally. The approaches to the hierarchy of structural strain levels and succession of their engagement in the materials subject to loading are described in $[2,3]$. The results of microscopic strain measurements of specimens subjected to plane-wave shock loading are presented in [4].

The aim of this paper is to determine both (i) quantitative correlation between continual values of strain and its values at a microscopic level and (ii) the change of these relations dependent 
on initial structure of the shock-loaded specimens. The attempt was made to analyze the high-rate plastic deformation mechanism in terms of the hierarchy of its structural levels established for a quasistatic strain. The experiments on explosive strain were performed with hollow thick-walled cylinders as proposed in [5]. The experimental arrangement is illustrated in Fig. 1 The authors selected this scheme for the following reasons:

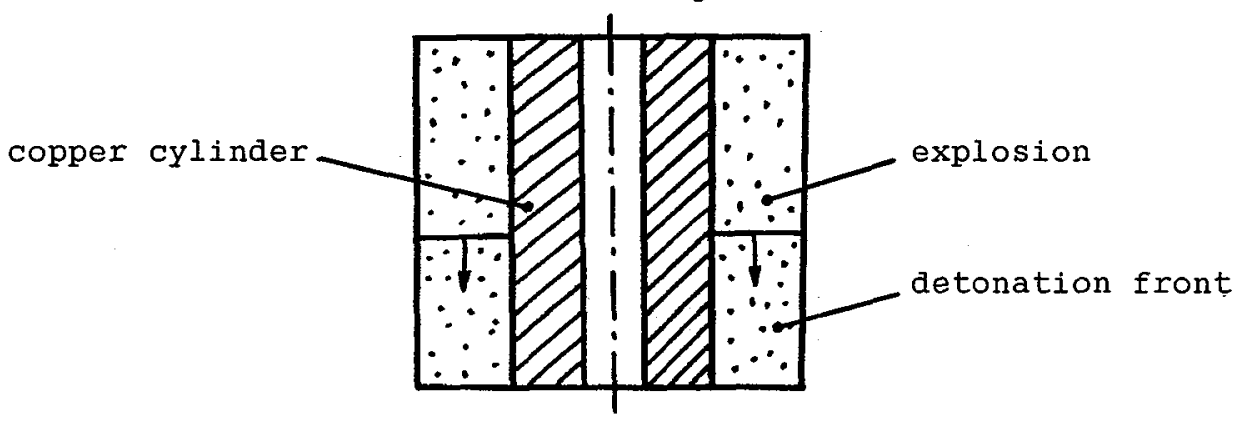

Fig.1.

1. A cylindrical geometry allows calculation of material strain at a continual level on the basis of initial and final radii [6] provided a medium is incompressible, and determination of strain velocity field by means of the measurement of the internal surface velocity.

2. A thick-walled cylinder conservs, due to its inertia, a symmetry of a specimen as a whole. Significant distortions may be avoided due to an invariable asymmetry of the detonation process. Due to high thickness of walls, the axial detonation velocity considerably exceeds the value of particle velocity; thus, a motion directed to a centre may be considered as a dominating one.

3. Copper was chosen as a typical representative of materials demonstrating a "hydrodynamical" behaviour under explosive loading. It was also used as a model material to study the processes responsible for the bond formation under explosive welding [5] and compaction of powders [8]. Besides, the unexpected effect of shear strain localization was observed in copper upon collapsing of a cylinder, as a result of which a system of helical cracks was formed [5]. And, after all, this choice is due to the presence of annealing twins in copper which allow quantitative measurements of residual microstrains.

The microstrains $\varepsilon_{r}, \varepsilon_{\varphi}$ of the material may be calculated from an initial position $(r)$ of some its element and a final one, $\rho$ [6]:

$$
\begin{aligned}
& \varepsilon_{\varphi}=\frac{\rho}{r}-1=\frac{\rho}{\left(b_{0}^{2}-b_{1}^{2}+\rho^{2}\right)^{1 / 2}}-1, \\
& \varepsilon_{r}=\frac{r}{\rho}-1=\frac{\left(b_{0}^{2}-b_{1}^{2}+\rho^{2}\right)^{1 / 2}}{\rho}-1 .
\end{aligned}
$$


Here $b_{0}, b_{1}$ are the initial and final external radii of a cylinder. Just $b_{0}$ and $b_{1}$ were used in the calculations, because $b_{1}$ may be measured with a higher accuracy than an final radius $a_{1}$. The estimated initial microstrain rate $\varepsilon_{r}\left(r=a_{0}\right)$ is $2 \cdot 10^{5} \mathrm{~s}^{-1}$

The cylinders with three types of initial structures were used in the studies: fine-grained ( $\mathrm{d} \simeq 50 \mathrm{mcm}$ ), row-grained $(\mathrm{d} \simeq \mathrm{n} \mathrm{mm}$ ) and row-grained layered structures. In the latter case, both the internal and external layers were dispersion-strengthened alloys, $\mathrm{Cu}-1$ vol. $\% \mathrm{Al}_{2} \mathrm{O}_{3}$, their initial thicknesses being $\simeq 0.75 \mathrm{~mm}$.

Its pronounced circular boundaries were revealed by etching. The present geometry made it possible to control a cylindrical symmetry of the process in the regions adjacent to the internal surface, where $\varepsilon_{r} \approx n \cdot 100 \%$ (Fig. 2).

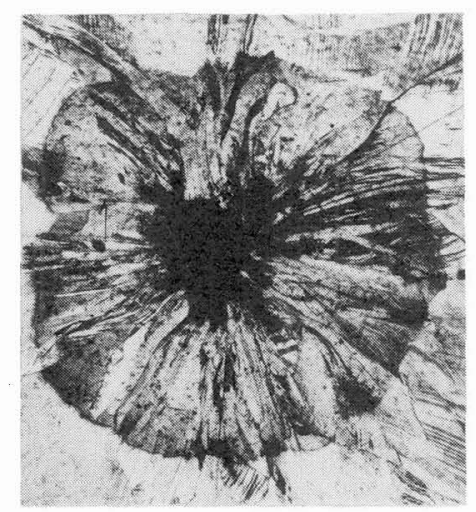

Fig. $2, \times 6$

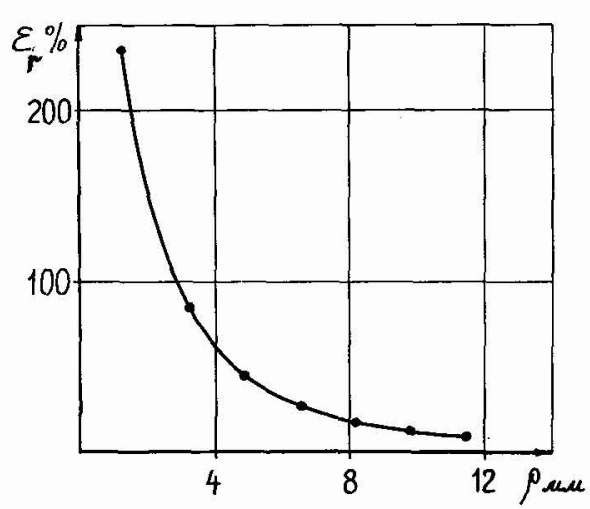

Fig. 3 .

After loading the cylinders under the same conditions, the strains $\varepsilon_{r}$ and $\varepsilon_{\varphi}$ were determined. The $\varepsilon_{r}(r)$ dependence is presented in Fig. 3. It should be noted that $\varepsilon_{r}$ variations observed near the internal surface of the cylinder are qualitatively analogous to shear strain $\varepsilon_{c}$ near the weld [7]. The microhardness $H_{v} \quad(P=50 \mathrm{~g})$ was measured, and the structure was analyzed both just after the explosion and recrystallization annealing at optimal temperatures [1].

Mutual for all the specimens is the presence of developed localized plastic deformation bands (LPDB) similar to the zones of intense plastic flow on contacts under explosive welding and compacting. The strain in the localized flow zones was measured via twins a part of which occured to be in the region of localized plastic strain. The value of $\varepsilon_{r}$ was measured using the expression 


$$
\varepsilon_{r}=\frac{1-1_{0}}{1_{0}}
$$

where $l$ is the length of the section (e.g., twin width) in the zone of localized plastic shear band, and $l_{0}$ is the initial value.To estimate $\varepsilon_{r}$, the twin initially normal to the radius was chosen (Fig. 4).

Radius $\rho$ corresponding to the middle of the twin (region $A$ ) was equal to $1.46 \mathrm{~mm}, 2 \mathrm{~b}_{1}=25.5 \mathrm{~mm}, 2 \mathrm{~b}_{0}=27.5 \mathrm{~mm}$. The measured value of $\varepsilon_{r \text { micro }}=3.64$, and $\varepsilon_{r \text { macro }}=2.66$. It should be noted that the region $B$ adjacent to $A$ did not undergo radial strain. Thus, it may be concluded that there are available the adjacent regions whose microstrains differ by several times, and macrostrains corresponding to the same radius essentially differ from microstrains.

The localized flow zone in fine-grained cylinders is bounded by the radius $\rho \simeq 3 \mathrm{~mm}(r \simeq 5.5 \mathrm{~mm})$, the continuum value being $\varepsilon_{r} \sim 100 \%$. At a distance of $\rho \sim 1 \mathrm{~mm}\left(\varepsilon_{\mathrm{r}} \sim 500 \%\right.$, cracking is developed along the bands of localized plastic shear (Fig. 5).

In row-grained cylinders, the first bands of localized shears are at a distance $\rho \sim 6.8 \mathrm{~mm}(r \sim 8.5 \mathrm{~mm})$, the continuum value of $\varepsilon_{r}$ being $26.5 \%$. As approaching to the centre, the number of localized shears inreases and the concentration gradient reaches the maximum at $\rho \sim 3 \mathrm{~mm}$. This effect manifests itself most pronouncely in the breaking of the interface between the inner-oxidization layer and the surrounding material and in the appearance of structural formations in this layer if the boundary is at a distance of $3 \mathrm{~mm}$ from the centre (Fig. 6).

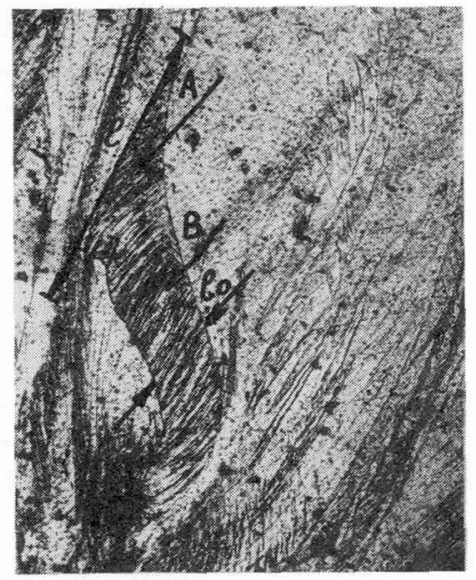

Fig. $4, \times 200$

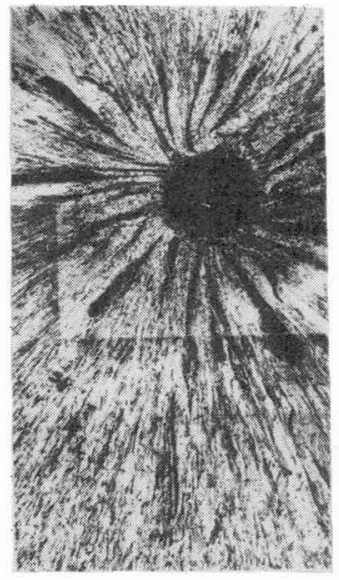

Fig. $5, \times 20$. 


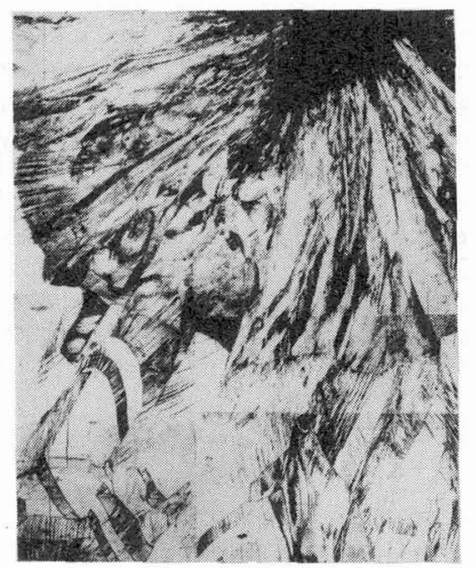

Fig. 6, $\times 14$.

The effect of the strengthening phase, in which the size of particles varies over the range 200 to $350 \mathrm{~A}$ and the distance between them is 800 to $1500 \mathrm{~A}$, on final strain structures of row-grained particles, has not been revealed. The radius $\rho \sim 3 \mathrm{~mm}$ is characterized by an abrupt increase in the continuum strain $\varepsilon_{r}$ (Fig. 3) and the development of localized plastic bands in fine-grained copper.

The variations in microhradness over the cross-sectional area of the deformed cylinder coincide with the flow structure (Fig. 7). In the centre of the cylinder, where $\varepsilon_{r} \approx n \cdot 1000 \%$, a strip-cast structure is observed, $H_{v}=60-70$ units. At a certain distance from the centre, one may distinguish three regions. Region 1 extending to the distance $\rho \approx 2 \mathrm{~mm}$ is characterized by a high frequency of local high values of microstructure. For Region II the mean values of $H_{v}$ are lower, the frequency of maximum $H_{v}$ is less and the distance from the outer boundary to the centre is, approximately, $6 \mathrm{~mm}$. The strengthening degree of periphery Region III is the lowest one.

It has been found that the initial grain size in cylinders affects not only the development of localized bands of plastic flow but also their structure. In the cylinders with the $50 \mathrm{mcm}$ grain size, the direction of these bands coincides with that of maximum shear stresses (Fig. 5). This demonstrates that (i) there is no relation between them and the system of crystallographic slipping and (ii) that plastic stability has been lost that corresponds to the transition of plastic flow to a macrolevel in the adopted hierarchy of structural strain levels.The direction of the localized bands immediately after the explosion in cylinders with row grains is difficult to be determined due to considerable distorsion in initial structures. Besides, each band may be interpreted to be the so-called rotational plate with respect to a 
grain. This is seen from the variations in slipping line directions in parts of the twin through which the localized plastic zone passes (Fig. 4). Besides, this is in agreement with the fact that shear strain accomodation in the band is due to rotational modes of strains in the grain volume surrounding it. Thus each of LPDB represents a structure fragment increasing the number of boundaries per unit square which mask the direction of localized plastic strains. Their geometry is evident in the structure obtained by recrystallization annealing at homologous temperature $T=0.4$ (Fig. 8). As is seen from Fig. 8, in row-grained cylinders, like in fine-grained ones, the presence of the bands is not associated with crystallographic structure. Their direction coincides with that of maximum shear stress.

By the adopted classification of structural levels of strain, the continual value $\varepsilon_{r}=30 \%$ corresponding to the development of the LPDB in row-grained structure, represents the boundary between the plastic strain realized via the motion of individual dislocations and the next level associated with the motion of their essemblies resulting in fragmentation of grain internal structure [3].

Accomodation of structural nonconformities at the translation shears is realized via rotational modes leading to the reorientation of fragmented structure. Under high-rate strain $\left(\varepsilon \geqslant 10^{5} \mathrm{~s}^{-1}\right)$ the loss of plastic stability and transition to the highest structural strain level, macrolevel at $\varepsilon_{r}=30 \%$, are indicative of the fact that the localization effect is amplified by the absence of uniform structural elements accomodating the translational shear due to the rotational modes. In fine-grained initial structure, propagation of the LPDB is observed in the region of high continual values of $\varepsilon_{r}$. In this case the elements accomodating the structural nonconformities due to translational shear are likely to be associated with small sizes of grains. The mechanism of accomodation processes in fine-grained specimens is responsible for the peculiarities of the structure of the plume-like strips (Fig.5) which are etching-resistant. They are similar to "white bands" which may appear in steel and other alloys under intensive plastic strain including explosive welding and strengthening.

It should be noted that there is the difference between the patterns of cracking of the specimens having different grain size. For fine-grained structure, the cracking is directly associated with the LPDB; in row-grained copper, the main cracks are connected with LPDB propagating to the region of low values of $\varepsilon_{r}$. Branchings of the main cracks pass along the grain boundaries or the IPDB corresponding to higher $\varepsilon_{r}$. 


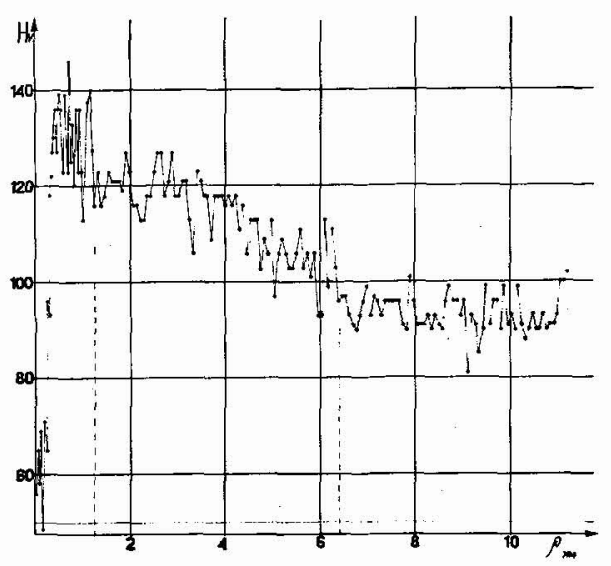

Fig. 7 .

For row-grained materials, the development of localized strains at higher structural level at lower values of $\varepsilon_{r}$ demonstrates that the material "refuses" to store the energy of plastic strain at lower structural levels under the given conditions of high-rate loading. This results in the decrease in specific heat release on contacting surfaces under explosive welding and compaction hampers the formation of the near-contact necessary-size region of intense plastic deformation. This may badly influence the conditions of bonding formation [1].

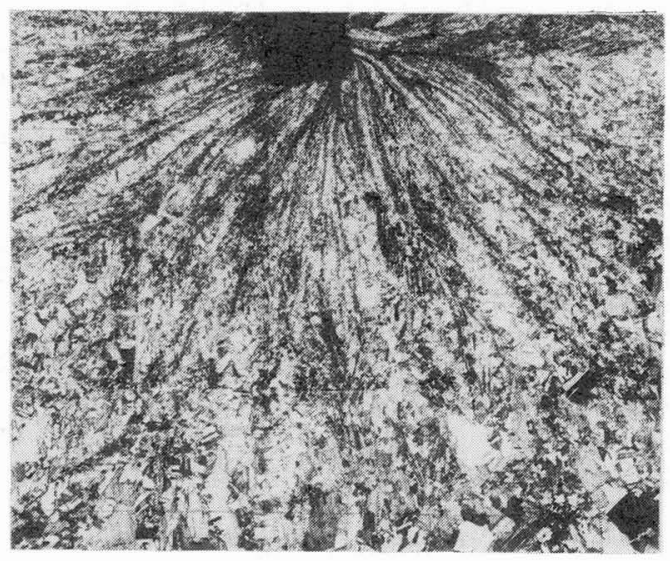

Fig. 8, $\times 11$.

Conclusions.

1. The method of studying the developed high-rate plastic strain 
based on explosive compression of thick-walled hollow cylinders has been proposed. It allows the zones with a controlled value of average strain $\left(\varepsilon_{r}, \varepsilon_{p}\right)$ to be obtained and thus the hierarchy of its structural levels and their dependence on an initial state of material to be studied. The instability of plastic flow in $\mathrm{Cu}$ developing into the system of cracks upon the cavity collapse has been first discovered.

2. The succession of engaging the hierarchy of structural strain levels is defined by the relation between the value of average strain rate at a continual level and the accomodation rate of internal stresses by rotational modes.

3. In fine-grained materials, the macrocrack formation folows the pattern of maximum shear stresses which are not associated with a crystalline structure. In row-grained copper, it has been established by the method of successive recrystallization that the patterns of maximum shear stresses coincide only for the bands of localized plastic strain, and there is a qualitative disagreement between the crack geometries in fine-grained structures.

4. A qualitative determination of the difference between the given continuum value of $\operatorname{strain} \varepsilon_{r}$ and its value at a microlevel gives the value $\sim n \cdot 100 \%$.

\section{REFERENCES}

11/ Bondar, M.P. and Nesterenko, V.F., Contact strain and criteria of bonding formation under dynamic loadins, Fizika goreniia i vzryva, vol.27, No.3 (1991), pp. 103-117.

12/ Panin, V.E., Iikhachov, V.A., Grinyaev, Yu.V. Structural strain levels of solid bodies, Novosibirsk, Nauka Publishers, $(1985), 163 \mathrm{p}$.

/3/ Rybin, V.v. Large plastic strains and metal fracture, Moscow, Metallurgiia Publishres (1986), $224 \mathrm{p}$.

/4/ Panin, V.E., Meshcheryakov, Yu.I., Yelsukova, T.F. et al. Noncrystal lographic structural strain levels in highly excited systems Izv. vysshikh uchebnykh zavedenii, ser. Fizika, No.2, (1990), pp.107-120.

15/ Nesterenko, V.F., Lazaridi, A.N., Pershin, S.A. Strain localization in copper under explosive compression of hollow cylinders, Fizika goreniia i vzryva, No.4, (1989), pp.

w. 154-155.

/6/ Ilyushin, A.A., Ogibalov, P.M. Elastoplastic strains of hollow cylinders, Izdatelstvo Moskovskogo Gosudarstvennogo Universiteta, Moscow (1960), $102 \mathrm{p}$.

17/ Bondar, M.P., Ogolikhin, V.M. On plastic deformation in the bonding zone under explosive cladding, Fizika goreniia i vzryva, No.2 (1982), pp.147-151. 